\title{
COMPARISON OF VACUUM SINTERED AND SELECTIVE LASER MELTED STEEL AISI 316L
}

\begin{abstract}
The paper presents the results of the basic mechanical properties determined in the static tensile test, impact un-notched Charpy test and hardness of austenitic stainless steel type 316L produced by two techniques: classical pressing and sintering in a vacuum with rapid cooling and selective laser melting (SLM). In this work fracture surface of Charpy test, samples were studied.

The results indicate that application of selective laser melting (SLM) makes it possible to double increase the strength properties of components manufactured from austenitic stainless steel type $316 \mathrm{~L}$ compared to sintering in a vacuum. Resulted in mechanical properties strongly depend on porosity characteristic and the presence of superficial oxides in the case of sintered steel and the character of observed microstructural defects deriving from non-fully melted powder particles and the formation of voids between subsequently melted pool tracks during the SLM.
\end{abstract}

Keywords: austenitic stainless steel, 316L, selective laser melting, SLM

\section{Introduction}

The selective laser melting (SLM) of austenitic stainless steel type $316 \mathrm{~L}$ is extensively studied for a few years, and high mechanical properties, especially in term of yield strength have been proven for SLM part, comparable to booth wrought and cast products made of this alloy [1].

The characteristic properties of additive manufacturing technique, such as SLM are a rapid crystallisation rate of subsequently melted powders layers that can influence on the high residual stress level of formed parts, crack formation and deformation of developed parts during processing or after separation from the base support $[2,3]$. The formed microstructures relate to the building direction, resulting in elongated grains parallel to the growing directions, having cellular-columnar morphology typical for the rapid cooling rate of high energy source processing technics $[4,5]$. That in summary with part orientation according to the support structure result in strong anisotropy effect in mechanical properties of SLM elements $[1,6]$. The anisotropy of mechanical properties of additive manufactured stainless steels is low in the $\mathrm{Z}$ direction, while in the $\mathrm{X}$ and $\mathrm{Y}$ axis it can be avoided by using an adapted laser strategy [1]. The key advantage of additive manufactured stainless steels is high part densities up to $99.9 \%$ that can be reached and fine microstructures with small residual porosity comparing to classic pressing and sintering method [7]. Beside numerous advantages, the SLM is not free of microstructural defects lowering structural integrity and influencing on overall mechanical properties of SLM parts.
The identification of microstructural defects in sintered parts as well as in SLM parts together with an explanation of their causes plays an important issue in all engineering materials, influencing on the base mechanical properties [14-17] and especially for laser based techniques [18].

This work was intended to compare basic mechanical properties resulted from a static tensile test at room temperature and dynamic Charpy impact test as well microhardness level of classic vacuum sintered and SLM austenitic stainless steel type 316L. The microstructural features of alloys produced by both technologies on the mechanical properties have been discussed.

\section{Experimental procedure}

The austenitic stainless steel powder 316LHD of Hoeganes type AISI 316L (C<0.019\%, Mn 0.1\%, Si 0.9\%, Cr 16.2\%, Ni $12.3 \%$, S $0.006 \%$, Mo $2.2 \%$, O $0.26 \%$, N $0.05 \%$, bal. Fe) with the particle size less than $45 \mu \mathrm{m} 49.84 \%$ and maximum of $150 \mu \mathrm{m}$ was applied for sintering by conventional compacting and vacuum sintering method. The powder was mixed with $0.65 \mathrm{wt} . \%$. of Acrawax lubricant to facilitate compacting step. The powder premix was homogenised in a Turbula mixer for $20 \mathrm{~min}$ and then uniaxial compacted at $700 \mathrm{MPa}$. Two specimen shapes were prepared: the "dog-bone" tensile sample (ISO 2740) and un-notched Charpy impact energy sample $10 \times 10 \times 55 \mathrm{~mm}$ (ISO 5754). The de-waxing process was performed at $550^{\circ} \mathrm{C}$ for 60 minutes in an $\mathrm{N}_{2}$ atmosphere. Samples were then sintered

\footnotetext{
SILESIAN UNIVERSITY OF TECHNOLOGY, FACULTY OF MECHANICAL ENGINEERING, INSTITUTE OF ENGINEERING MATERIALS AND BIOMATERIALS, 18A KONARSKIEGO STR., GLIWICE 44-100, POLAND 
in a vacuum furnace with $\mathrm{Ar}$ backfilling at $1260^{\circ} \mathrm{C}$ for $60 \mathrm{~min}$. During the sintering cycle a solution annealing at $1050^{\circ} \mathrm{C} / 1 \mathrm{~h}$ was done, and then the rapid cooling with the nitrogen of $0.6 \mathrm{MPa}$ was applied, giving the average cooling rate of $6^{\circ} \mathrm{C} / \mathrm{s}$. The vacuum sintered stainless steel showed density of $7.15 \mathrm{~g} / \mathrm{cm}^{3}(89.37 \%$ of theoretical density), total porosity $9 \%$ and open porosity $2.5 \%$.

The selective laser melting (SLM) of austenitic stainless steel powder $316 \mathrm{~L}$ type $(\mathrm{C}<0.024 \%$, Mn $1.25 \%$, Si $0.51 \%$, Cr $16.3 \%$, Ni $10.1 \%$, S $0.009 \%$, Mo $2.11 \%$, O $<0.1 \%$, N $<0.1 \%$, bal. Fe) with the particle size of $15-45 \mu \mathrm{m}$ was carried out on a Renishaw AM125 machine that employs a pulsed Nd: YAG laser with wavelength $1070 \mathrm{~nm}$ with the maximum average power of $200 \mathrm{~W}$ and a spot size of $35 \mu \mathrm{m}$. The layer thickness of melted powder in a single pass was $50 \mu \mathrm{m}$. A meandering pattern is used to scan each layer. After the layer is completed, the recoater is the returned to the powder doser and the process repeats. When the next layer is scanned, the same pattern as used in the previous layer is rotated by $60^{\circ}$ and translated a specified amount to prevent the same points from being exposed multiple times in subsequent layers.

The device was also equipped with two oxygen sensors to ensure low oxygen content during the manufacturing process. Before starting the process, the chamber was flooded with $99.996 \%$ pure Argon until a value below $0.1 \%$ oxygen was reached. During the manufacturing of the specimens, the chamber was continually flooded with Argon guaranteeing a low oxygen content. With that process, an oxygen content of around $100 \mathrm{ppm}$ was achieved. The SLM samples for tensile test: the "dog-bone" sample (ISO 2740) and un-notched Charpy sample $10 \times 10 \times 55 \mathrm{~mm}$ (ISO 5754) were built on a steel plate of $125 \mathrm{~mm} \times 125 \mathrm{~mm}$ and were fabricated horizontally with their length direction, parallel with the surface of the steel substrate plate - the horizontal direction XY. The SLM samples were studied as received after SLM process, without any subsequent heat treatment. The SLM stainless steel showed the density of $7.70 \mathrm{~g} / \mathrm{cm}^{3}$, that is $96.25 \%$ of theoretical density.

Studied samples were tested on a ZWICK Z100 machine adopting the tensile test procedure included in ISO 6892-1 for studied samples, thus ultimate tensile strength (Rm), $0.2 \%$ yield strength (Rp0.2) and elongation after fracture (At) were measured. The Charpy impact test on a ZWICK RKP300 was performed on un-notched samples to determine the impact toughness. The hardness measured on the sample top surface was determined through Vickers scale (HV1).

Microstructures observations and fracture surface analysis were carried on the Scanning Electron Microscope SUPRA 25 of ZEISS Company equipped with the EDS probe. The optical microscopy was also involved after sample electrolytic etching in oxalic acid.

\section{Results and discussion}

The microstructure of vacuum sintered and SLM austenitic stainless steel powder type 316L are presented in (Figs. 1,2).
The microstructure of the sintered sample shows well-developed twin boundaries and precipitate free grain boundaries of austenitic grains of a medium size (Fig. 1). Present porosity between grains is circular and between primary powder particles more irregular but preferentially rounded. The level of porosity is typical for adopted conditions of vacuum sintering with a rapid cooling stage.

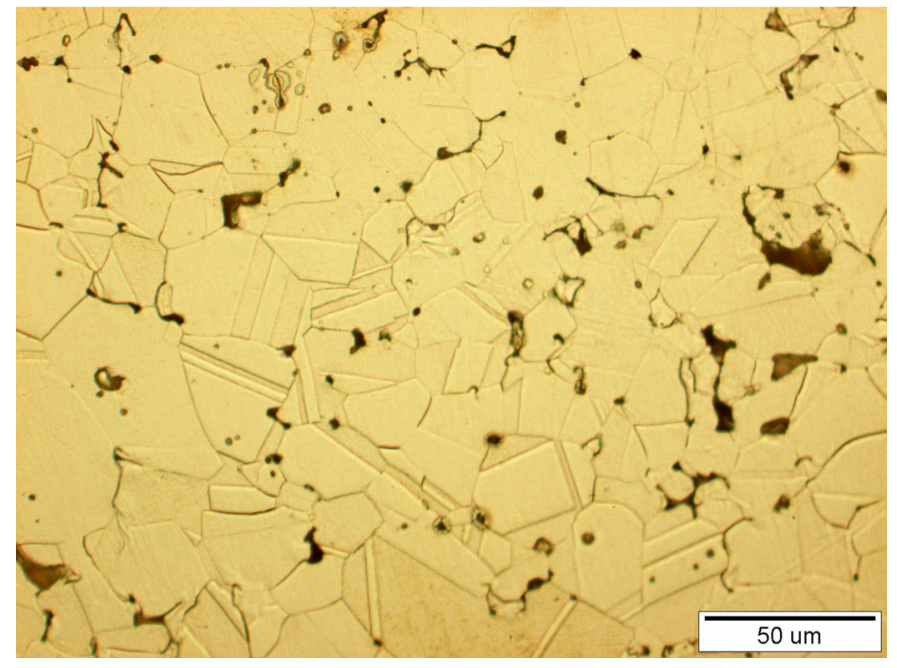

Fig. 1. Microstructure of $1260^{\circ} \mathrm{C} / 60 \mathrm{~min}$. vacuum sintered AISI $316 \mathrm{~L}$

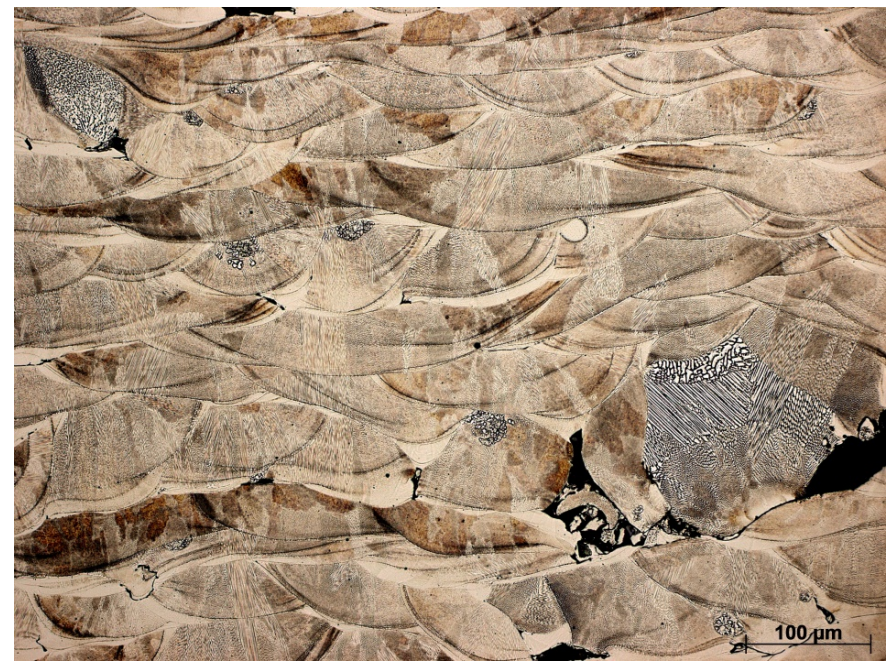

Fig. 2. Microstructure of SLM stainless steel type AISI 316L

The microstructure of SLM austenitic stainless steel in as received state after SLM process, without any subsequent heat treatment is typically composed of overlapped melted pool tracks with crystallised grains of cellular-columnar structure oriented according to thermal gradient direction. The cellular-columnar microstructure is typical for stainless steel solidified under fast cooling rate, as for sources of high energy, like laser radiation [13]. In the microstructure, some voids located between subsequent melt layers were revealed that could be associated with non-fully melted powder particles (Fig. 2). Observed defects described in the literature [8] as related to poor wetting of the melt pool on the deposited solid layer can be associated with 
the presence of superficial oxides. The randomly distributed spherical porosity inside molten scan tracks was hardly evidenced in the microstructure, and their presence is related to gas entrapment during layer building [8]. The parameters of SLM selected in this study were optimised to limit microstructural defects and increase full bonding of subsequently melted layers. The best properties are obtained for increased laser power density or decreasing scanning velocity, which leads to lower porosity, bigger melt pool and stronger bonding between pools [3]. Besides that, numerous microstructural defects typical for SLM technology were identified in the steel microstructure, i.e. voids between melted pools of different size (Fig. 3a, d), nonfully melted powder particles, that show the dendritic microstructure between fully melted and well developed cellular grain microstructure (Fig. 3b), small spherical porosity preferentially located between molten pools (Fig. 3c). The cellular-columnar grain microstructure reveals variable directional grow, where subsequent motel pool layers overlap, and sub-micro grains change growth direction, showing epitaxial columnar growth (Fig. 4). Similar growth perturbation occurs near slowly solidified powder particles, not fully melted in initial process stage, having a higher overcooling rate, thus showing preferentially dendritic microstructure (Fig. 4d).

a)

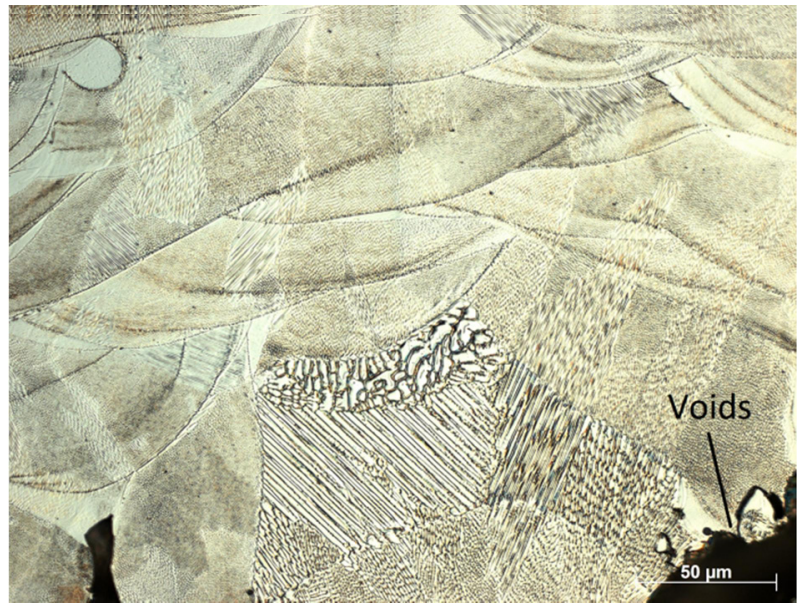

c)

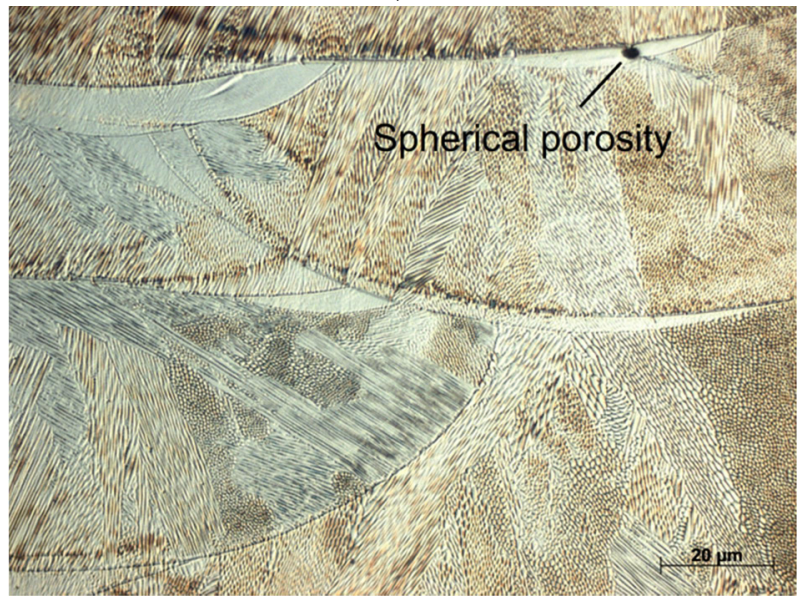

The comparison of basic mechanical properties of sintered and SLM austenitic stainless steel type AISI 316L is listed in Table 1. Vacuum sintered austenitic stainless steels with rapid cooling directly from the sintering temperature (sinter-hardening) show lower mechanical properties in term of tensile, yield strength as well as elongation values comparing to SLM samples. The hardness of sintered samples was two times lower than for SLM, accordingly 110 and $215 \mathrm{HV} 1$. Tested steel samples submitted to the un-notched Charpy impact test showed impact energy values of $118 \mathrm{~J}$ for classic sintering in a vacuum, while for SLM samples it was double, c.a. 250J.

TABLE 1

Mechanical properties of sintered and SLM austenitic stainless steel type AISI $316 \mathrm{~L}$

\begin{tabular}{|c|c|c|c|c|c|}
\hline \hline $\begin{array}{c}\text { Manu- } \\
\text { facturing } \\
\text { process }\end{array}$ & $\begin{array}{c}\text { Yield } \\
\text { strength } \\
\text { Rp0.2, } \\
\text { MPa }\end{array}$ & $\begin{array}{c}\text { Tensile } \\
\text { strength } \\
\text { Rm, MPa }\end{array}$ & $\begin{array}{c}\text { Elongation } \\
\text { At, \% }\end{array}$ & $\begin{array}{c}\text { Hard- } \\
\text { ness, } \\
\text { HV1 }\end{array}$ & $\begin{array}{c}\text { Impact } \\
\text { tough- } \\
\text { ness, J }\end{array}$ \\
\hline $\begin{array}{c}\text { Vacuum } \\
\text { sintering }\end{array}$ & $200 \pm 2$ & $435 \pm 5$ & $18.0 \pm 0.5$ & $110 \pm 10$ & $118 \pm 2$ \\
\hline SLM & $539 \pm 3$ & $600 \pm 3$ & $28.0 \pm 0.5$ & $215 \pm 10$ & $253 \pm 10$ \\
\hline
\end{tabular}

b)

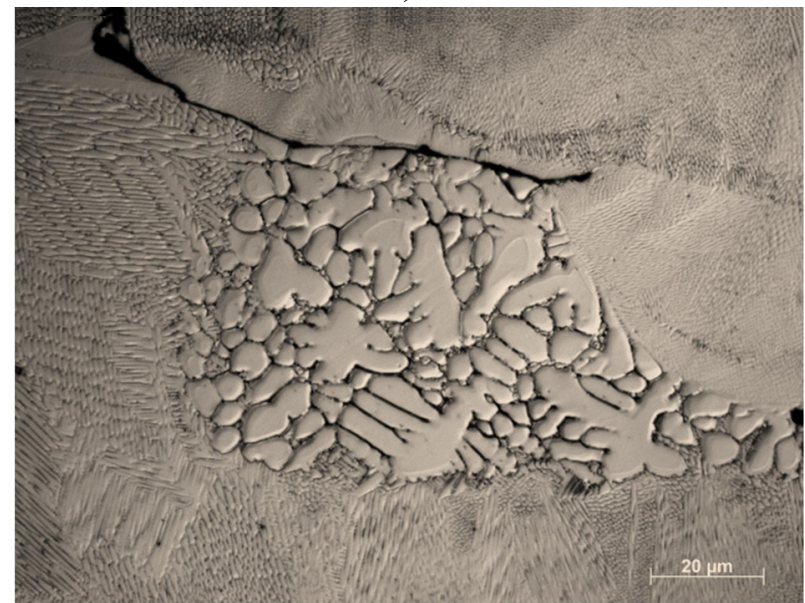

d)

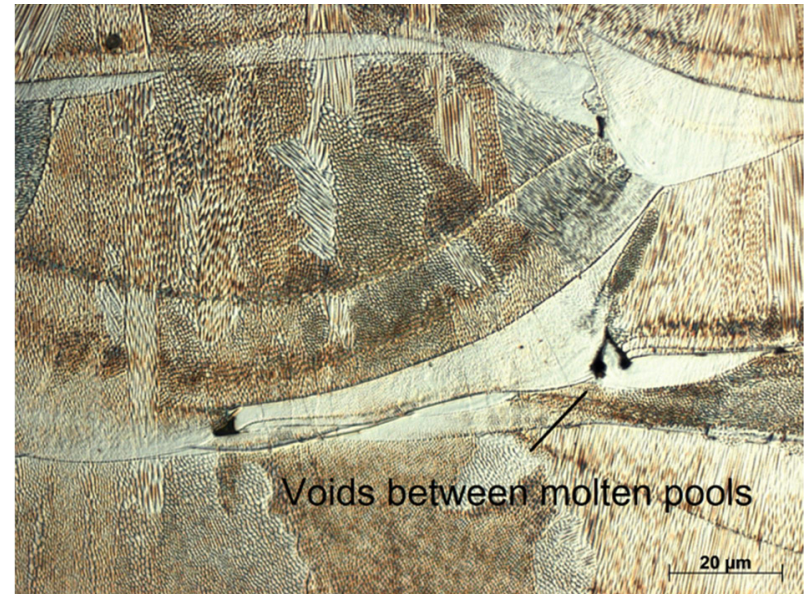

Fig. 3. The microstructure details in SLM stainless steel type AISI 316L 
a)

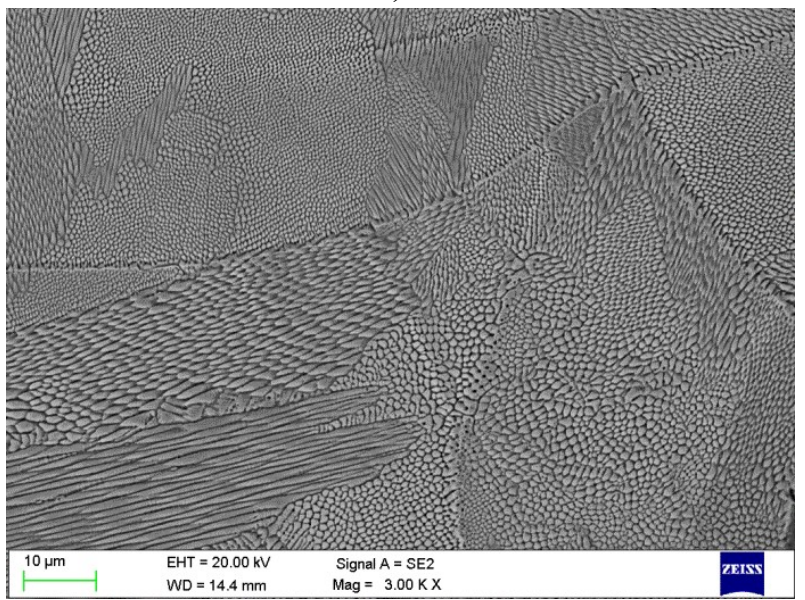

c)

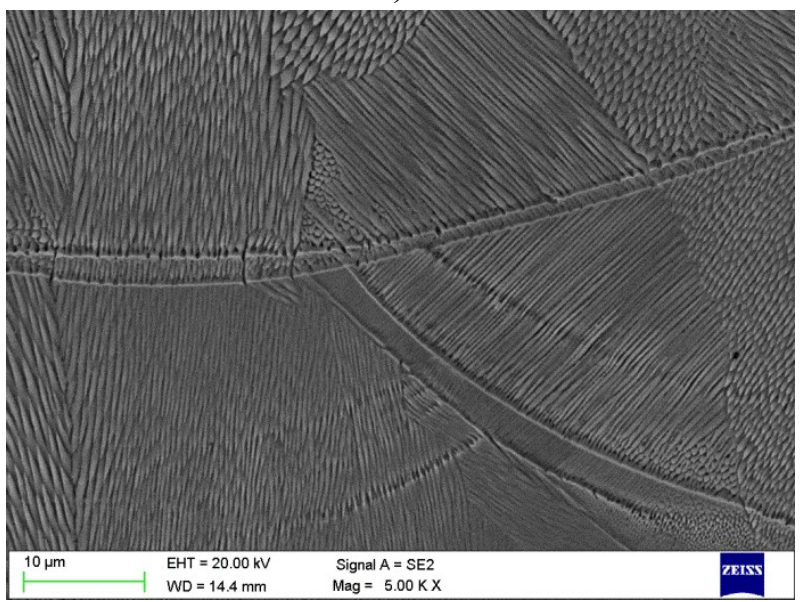

b)

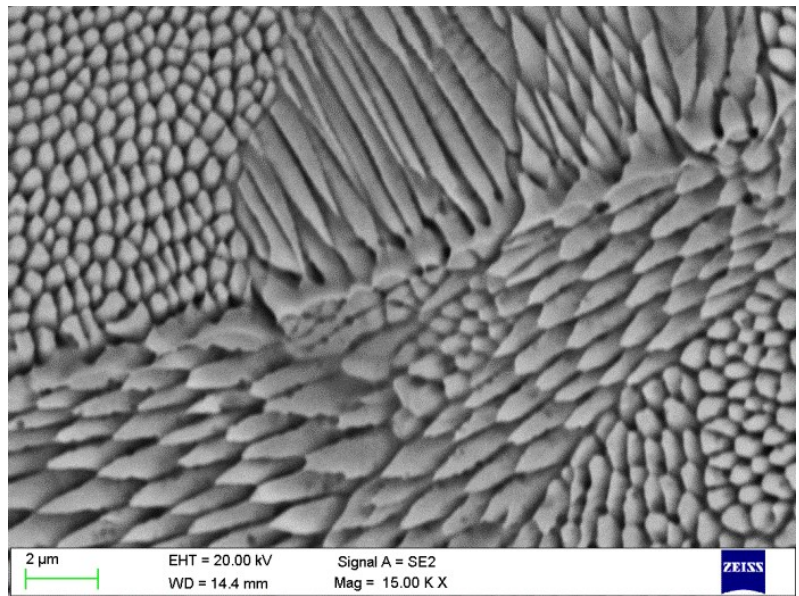

d)

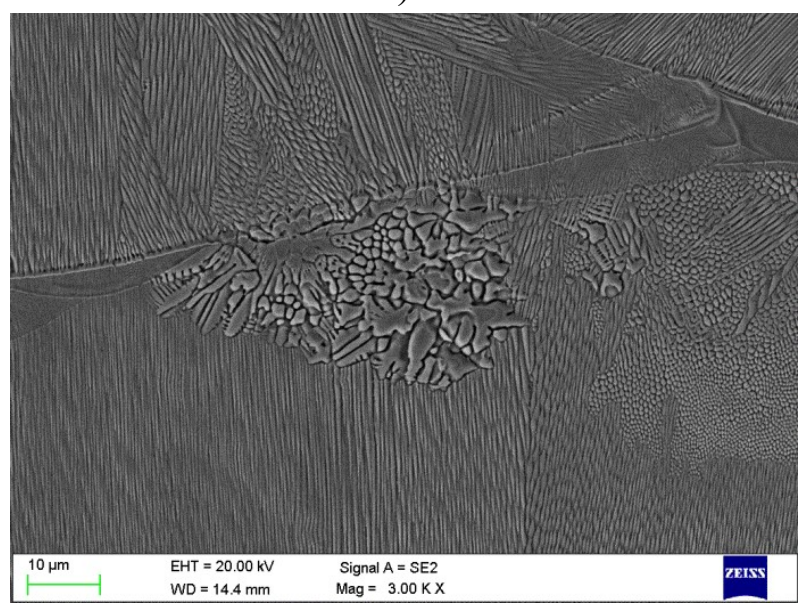

Fig. 4. The microstructure details in SLM stainless steel type AISI 316L

The fractography analysis of un-notched Charpy samples sintered in vacuum demonstrated that fracture surfaces show ductile type character and they clearly underline the presence of dimples throughout all examined surface (Fig. 5a,b). The fracture surface is composed of round primary porosity $(5-15 \mu \mathrm{m})$ between sintered powder particles (Fig. $5 \mathrm{c}$ ) and small oval dimples $(3-5 \mu \mathrm{m})$ located along plastic deformation zones (Fig. 5d), where necking of primary bonded powder particles occurred during braking stage. In the vicinity of some primary pores, where inter-particle bonding takes place during sintering, the agglomerates of complex oxides were also evident (Fig. 5d). The composition of formed oxides, studied by EDS analysis was predominantly silicon ( $51 \%$ wt.), iron and chromium (Fig. 6). Thus observed complex oxides can be associated with $\mathrm{SiO}_{2}, \mathrm{Fe}_{2} \mathrm{O}_{3}$, and $\mathrm{Cr}_{2} \mathrm{O}_{3}$ species also reported in the literature for stainless steels, where the silicon dioxide $\mathrm{SiO}_{2}$ one is the most detrimental for a proper particle bonding during sintering. The surface oxides on the powder particle do not fully undergo reduction during sintering at $1260^{\circ} \mathrm{C}$, and they also concentrate in the primary porosity, due to preferential displacement to these zones, while the necking fronts propagate and powder particles become connected. The balanced content of silicon and manganese in the sintered powder (water-atomised) give an average oxygen content of ca. $0.2 \%$, in the study it was $0.26 \%$. The vacuum sintering is well known for its excellent oxide reduction characteristic that in combination with rapid cooling stage after sintering with argon backfilling (sinter-hardening) prevent the excessive formation of detrimental surface oxides. Besides that, low level of carbon in the powder $(<0.02 \% \mathrm{C})$, that facilitate reduction is usually insufficient to reduce superficial oxides fully. During sintering in partial pressure of Ar the reduction process proceeds due to the reaction of residual carbon and oxides resulting in the formation of gaseous products [9]; thus superficial oxides are eliminated. The present powder contains $0.9 \%$ of silicon. Therefore, its particles are mainly covered with silicon dioxide, that is hardly reduced for low carbon powders. The silicon dioxides are reduced in temperatures above $1290^{\circ} \mathrm{C}$, while other oxides like chromium or manganese start to decompose at low temperatures $\left(900-1200^{\circ} \mathrm{C}\right)$, of course in dependence on the pressure conditions. The temperature of sintering is the most affecting parameter in the sintering process responsible for the superficial oxide reduction, interparticle bonding and pore rounding process. The unreduced oxide particles among others give lower dynamic mechanical properties like impact toughness of sintered stainless. Applied sintering temperature $1260^{\circ} \mathrm{C}$ result in a reasonable oxide reduction thus providing excellent 
mechanical properties, ductility and impact strength of studied sinters. To achieve better properties for a studied method the elevated-temperature sintering, such as $1315^{\circ} \mathrm{C}$ should be applied. As described in the literature the tensile strength of sinters is strongly affected by superficial unreduced oxide compounds, while the yield strength is less sensitive [10]. Obtained results of applied sintering time and temperature for a vacuum atmos- phere are comparable to literature dates $[10,11]$ regarding typical mechanical properties - yield and tensile strength and impact toughness, but the elongation was slightly lower $18 \%$, where the typical elongation value of such process and density level can reach up to $22 \%$. The hardness level is typical for a given porosity level and applied cooling procedure. Resulted hardness also confirms precipitates free microstructure of sintered alloy, a)

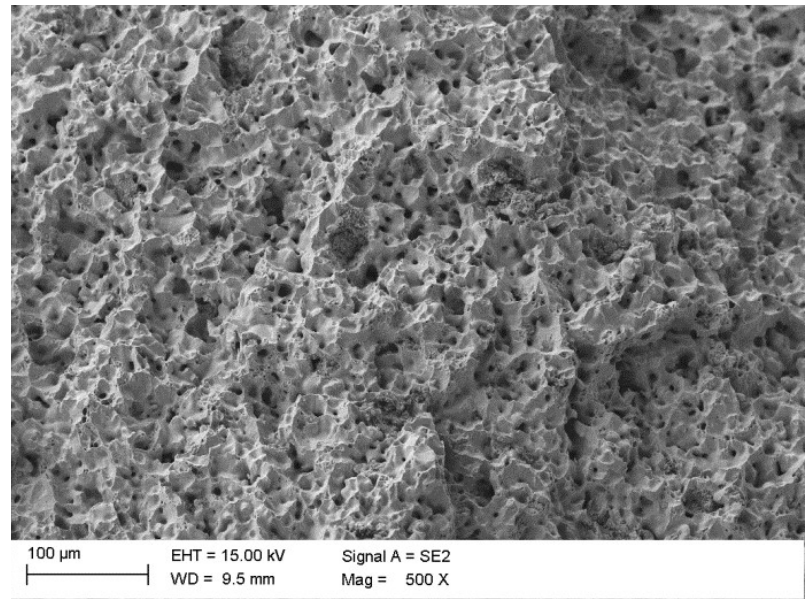

c)

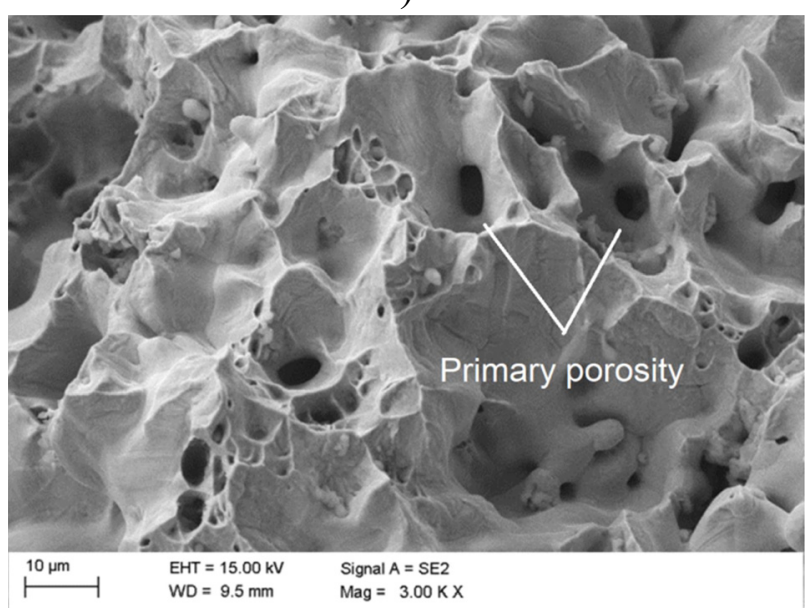

b)

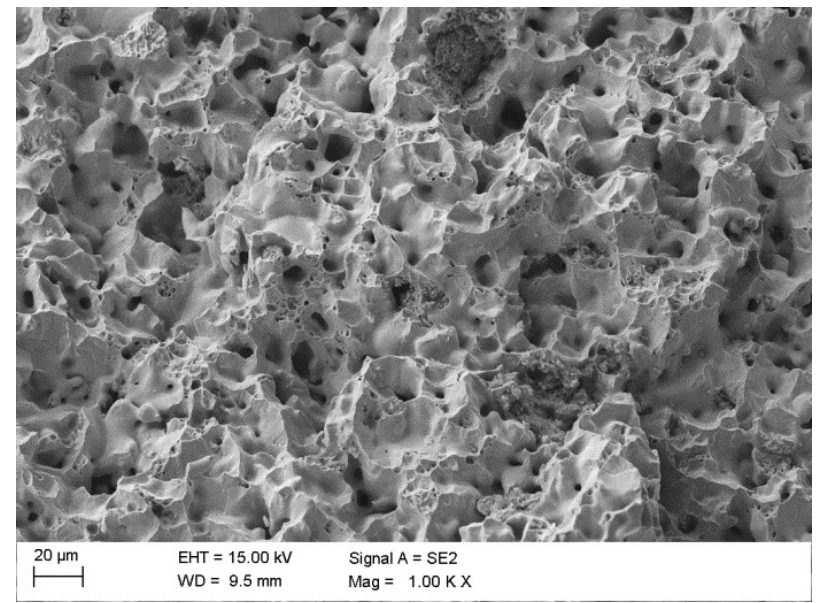

d)

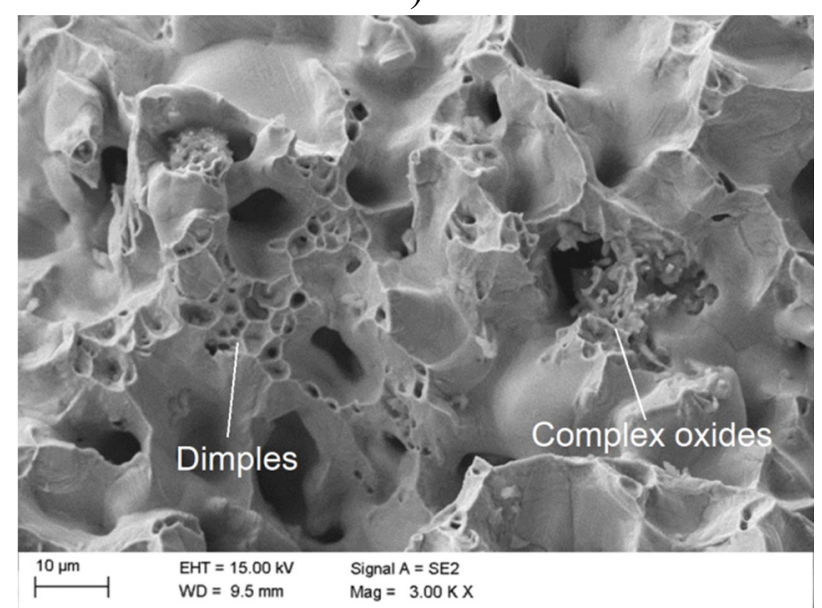

Fig. 5. Fracture surfaces of vacuum sintered stainless steels type AISI 316L

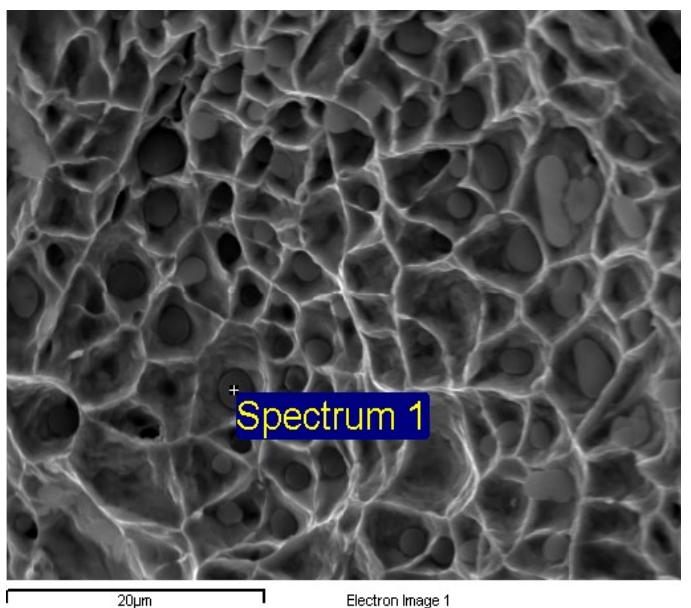

\begin{tabular}{|c|c|c|}
\hline Element & Weight \% & Atomic\% \\
\hline $\mathrm{Si}$ & 51.1 & 67.0 \\
\hline $\mathrm{Cr}$ & 17.1 & 12.1 \\
\hline $\mathrm{Fe}$ & 29.3 & 19.4 \\
\hline $\mathrm{Ni}$ & 2.3 & 1.5 \\
\hline
\end{tabular}

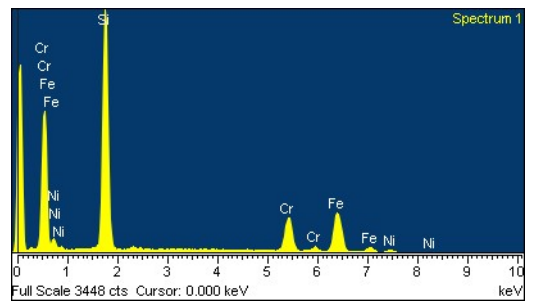

Fig. 6. The result of EDS analysis in the dimples area where complex oxide compounds were observed 
The large plastic deformed surface of SLM samples is much

which could be hardened by secondary phase precipitations during a slow cooling stage and giving higher hardness values and lower toughness value.

In a case of SLM the fracture surface of un-notched Charpy samples show completely different character, where large fracture regions of plastic deformation and zones of ductile deformation composed of micro-dimples were visible (Fig. 7a), but in macro scale, it seems more brittle than for vacuum sintered one. The ductile dimples were much smaller than in the case of vacuum sintered alloy, and preferentially occurred at the end of plastic deformed melt tracks regions (Fig. 7b). In the area of the interconnected primary cell (large voids), where melt tracks overlap, the presence of small circular non-fully melted powder particles was also observed (Fig. 7c). The insufficient melting in un-overlapped regions between adjacent melt pools can imprison powder particles, where the presence of such defects is typical for SLM process and hard to fully eliminate. Selected SLM parameters must be balanced to preserve the formation of undesired effects like balling phenomena connected with the insufficient wetting ability of the substrate layer by the molten material, that cause the liquid spheroidizing. In the present study, the balling effect of molten liquid was observed in the voids area between molten pools, where spheroidal molten particles were entrapped (Fig 7c).

a)

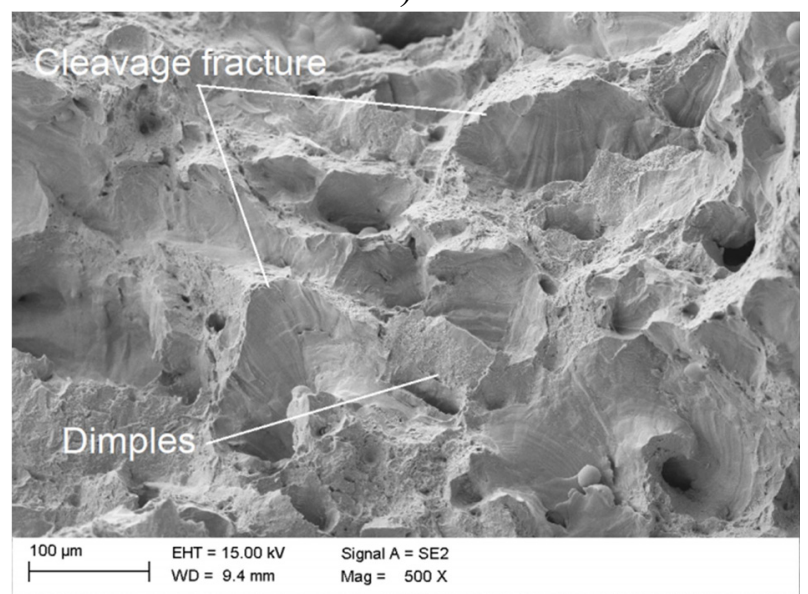

c)

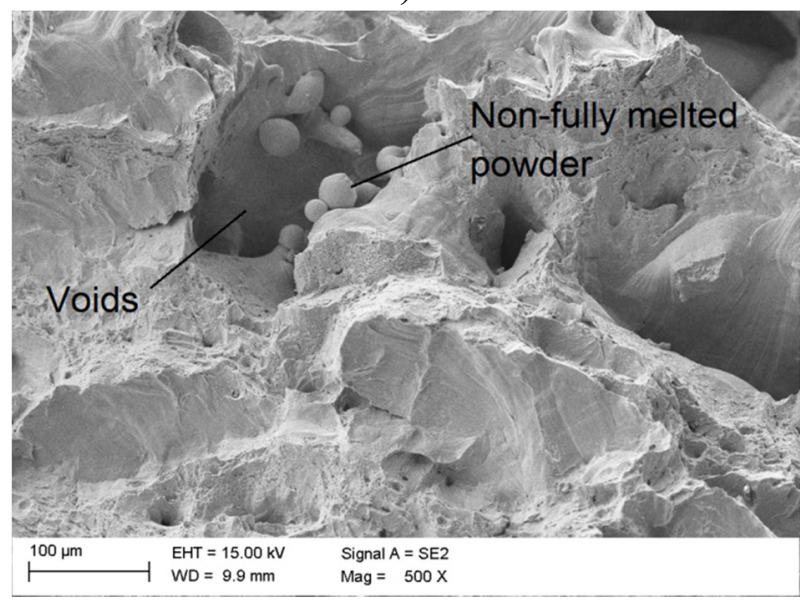

more non-regular with higher elevations and hollow zones and as an entire can be considered as ductile, but at the tip end of deformed zones the fracture character is more mixed, revealing more cleavage fracture on a microscale (Fig. 7d). The surface of the fractured region, where the final breaking occurred, is covered by micro and nano-sized dimples.

The mechanical properties of SLM austenitic 316L alloy have been recently studied in the literature [12], and improved mechanical characteristic (yield strength) of such prepared parts was associated with an intragranular cellular segregation effect. The strengthening mechanism was deriving from segregation of Mo at the cellular boundaries creating sites of residual stress concentration. Molybdenum segregation together with oxide nano-inclusions block the dislocation motion and effectively slow crack propagation, that result in increased yield strength and elongation after fracture.

When comparing mechanical properties of SLM alloy presented in this study to the literature dates (YS $=487 \mathrm{MPa}$, $\mathrm{UTS}=594 \mathrm{MPa}, \mathrm{A}=49 \%$ ) [12] those are on the same level, except to the elongation that is well below reported values. For such results are probably responsible high quantity of microstructural defects especial located on the overlapped melted pool tracks, like balling effect and non-fully melted powder particles.

b)

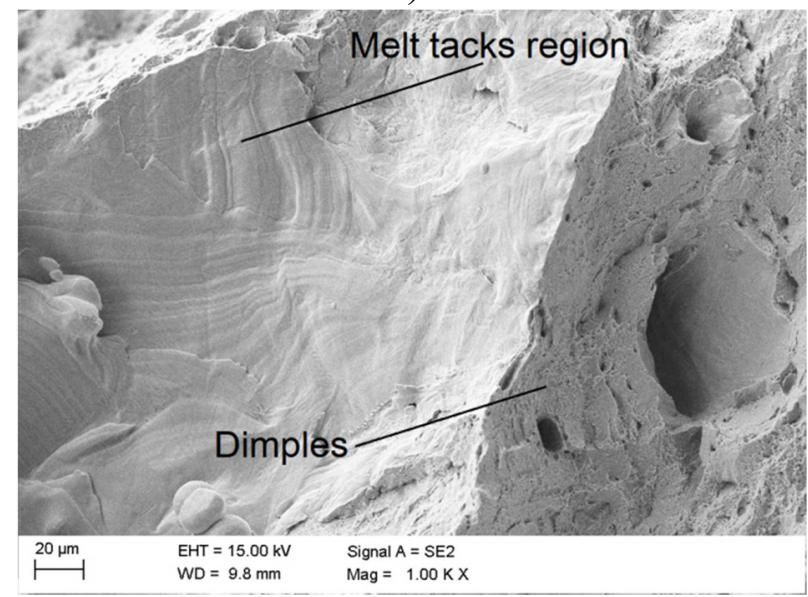

d)

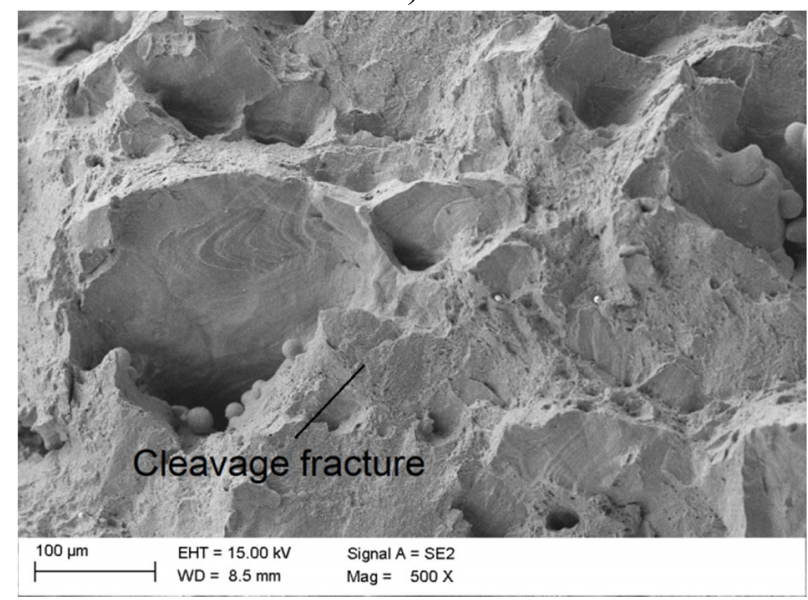

Fig. 7. Fracture surfaces of SLM stainless steels type AISI 316L 


\section{Conclusions}

The mechanical properties of vacuum sintered stainless steels are lower than those obtained in SLM process. The tensile properties and related fracture mode are determined by effective oxide reduction during sintering and temperature-controlled diffusion process leading to stronger bonding between powder particles, porosity reduction and pore rounding process. The higher contact areas between powder particles and rounded porosity the more plastic deformation zones of dimples character will be created during cracking. The nature of primary porosity plays a decisive role in a tensile characteristic of sinters, being sites of stress concentration together with interparticle weakly bonded sites due to the superficial oxides presence.

The SLM provided higher mechanical properties of melted austenitic stainless steel, c.a. double when compared to vacuum sintered. In this case also microstructural defects play a principal role in a uniform stress distribution during static or dynamic loading. The plasticity level is also well below that obtained for wrought stainless steel alloys ( $\min .45 \%$ ), but as deriving from the literature [12], it can be readily achieved. In the present study SLM parameters still need to be tuned especially to reach higher elongation afar fracture, while other mechanical properties (yield and tensile strength) reach comparatively high level.

\section{Acknowledgement}

This work was supported by the Ministry of Science and Higher Education of Poland as the statutory financial grant of the Faculty of Mechanical Engineering, Silesian University of Technology. Special acknowledgements to Dr Wojciech Pakieła for his help in the sample preparation for microstructural analysis.

\section{REFERENCES}

[1] I. Tolosa, F. Garciandia, F. Zubiri et al., Int. J. Adv. Manuf. Technol. 51, 639-647 (2010).

[2] I. Yadroitsev, I. Yadroitsava, Virtual Phys. Prototyp. 10 (2), 67-76 (2015).
[3] M. Król, M. Kujawa, L.A. Dobrzański, T. Tański, Arch. Mater. Sci. Eng. 67 (2), 84-92 (2014).

[4] Z. Brytan, M. Bonek, L.A. Dobrzański, D. Ugues, M.A. Grande, Mat. Sci. Forum, 654-656, 2511-2514 (2010).

[5] A. Mertens, S. Reginster, H. Paydas, Q. Contrepois, T. Dormal, O. Lemaire, J. Lecomte-Beckers, Powder Metall. 57 (3), 184-189 (2014).

[6] A. Mertens, S. Reginster, Q. Contrepois, T. Dormal, O. Lemaire, J. Lecomte-Beckers, Mat. Sci. Forum, 783-786, 898-903 (2014).

[7] E. Yasa, J.-P. Kruth, Procedia Eng. 19, 389-395 (2011).

[8] A. Mertens, S. Reginster, Q. Contrepois et al., Mat. Sci. Forum, 783-786, 898-903 (2014)

[9] R. Bidulsky, E. Hryha, J. Bidulska, High Temp. Mater. Proc. 35 (9), 865-870 (2016).

[10] E. Klar, P. Samal, Powder Metallurgy Stainless Steels: Processing, Microstructures and Properties, ASM International, Ohio, USA, 2007.

[11] C. Bossi, G.L. Garagnani, M. Rosso, Powder Metallurgy Progress 2, 2, 90-97 (2002).

[12] Y. Zhong, L. Liu, S. Wikman, D. Cui, Z. Shen, J. Nucl. Mater. 470, 170-178, (2016).

[13] L.A. Dobrzański, T. Tański, A.D. Dobrzańska-Danikiewicz, E. Jonda, M. Bonek, A. Drygała, Structures, properties and development trends of laser surface treated hot-work steels, light metal alloys and polycrystalline silicon, in: J. Lawrence, D. Waugh (eds.), Laser Surface Engineering. Processes and Applications, Woodhead Publishing Series in Electronic and Optical Materials, Elsevier Ltd, Amsterdam, 2015.

[14] M. Staszuk, D. Pakuła, T. Tański, Mater. Tehnol. 50/5, 755-759 (2016).

[15] M. Król, T. Tański, P. Snopiński, B. Tomiczek, J. Therm. Anal. Calorim. 127, 299-308, (2017). DOI:10.1007/s10973-016$-5845-4$.

[16] M. Król, T. Tański, W. Sitek, IOP Conf. Ser-Mat. Sci. (MODTECH2015) 95, (2015). DOI:10.1088/1757-899X/95/1/012006.

[17]. P. Snopiński, T. Tański, K. Labisz, S. Rusz, P. Jonsta, M. Król, Int. J. Mater. Res. 107 (7), 637-645, (2016). DOI: 10.3139/146. 111383.

[18]. M. Król, P. Snopiński, B. Tomiczek, T. Tański, W. Pakieła, W. Sitek, P. Est. Acad. Sci. 65 (2), 107-116, (2016). DOI: 10.3176/ proc.2016.2.07. 